\title{
An Educational Coding Laboratory for Elementary Pre-service Teachers: A Qualitative Approach
}

\author{
http://dx.doi.org/10.3991/ijep.v6i1.5364 \\ Leticia Vaca-Cárdenas, Assunta Tavernise, Francesca Bertacchini, Lorella Gabriele, Antonella Valenti, \\ Pietro Pantano, and Eleonora Bilotta \\ University of Calabria, Arcavacata di Rende, Cosenza, Italy
}

\begin{abstract}
The present study involved 64 pre-service teachers in a first experience of coding with the software Scratch, foreseeing its qualitative evaluation. In particular, the procedure in the laboratorial setting was designed as follows: firstly, subjects attended theoretical lessons on the use of the software, ideated and implemented an educational app. Afterwards, subjects wrote a report on the negative and positive aspects of their laboratorial experience.

The analysis of results show that pre-service teachers appreciated the collaborative work, the freedom to code an app following their own interests, and the use of an engaging software. A constant concern regarding teachers' selfefficacy as future mentors was present. Further quantitative studies are necessary.
\end{abstract}

Index Terms-Advanced technology-enhanced settings, coding, design of educational setting, education, higher education, HCI, High Order Think Skills, learning, projectbased learning, learning-teaching methodologies, Scratch.

\section{INTRODUCTION}

Nowadays, in didactic process, the necessity of learning complex scientific contents as well as the opportunity to use innovative media at school, have originated questions on the cognitive, behavioral, and social development of the "digitally born" generation [1], [2], [3]. Hence, both the reinvention of educational institutions and an advanced proper training for teachers have also been considered, in order to change the vision of the school, perceived as a world apart by students [4]. In this view, Universities have started to examine the warning signals of the present, reflecting on the kind of "educational theory" they want to refer to in the current evolutionary scenario, also defining the training objectives in pre-service teachers' courses.

Regarding a training on coding for elementary school teachers, many research have confirmed a general low level of scientific and technological knowledge [5], and a scarce level of perception of science teaching self-efficacy [6].

On the other side, the figure of a teacher as mentor (guide, advisor and counselor to a mentee) has been promoted [7], [8], seeing mentoring as less hierarchical but more relational and reciprocal in comparison to teaching [9]. Moreover, several programming clubs (Coderdojos) for young people have been realized for introducing the basic concepts of coding, also encouraging creativity, enjoyment, and engagement [10], [11].
The proposed exploration of technology in an informal and innovative environment has led to a world phenomenon called "The Hour of Code" [12], when an explicit emphasis has been devoted to the showing of coding as a driven force for changing the world. In fact, from an educational point of view, digital literacy has started to be regarded as helping to become a citizen of the XXI century [13], [14], [15], [16]. Furthermore, programming has begun to be considered the cause of the development of logical skills and ability [17], [18], related to a creative and efficient problem solving [19], [20], [21], [22], [23].

In Italy, on the basis of the US successful experience with forty millions of students and teachers, the Education Ministry has decided to establish the learning of computer science basic concepts in school curriculum.

The first reference has been the Circular $\mathrm{N}^{\circ} 002937$ (published in the official register on the 23rd of September, 2014) on the importance of coding at school. However, in the fundamental document called "La Buona Scuola" ("The Good School"), the fourth chapter has entirely been devoted to the teaching and focused on the development of High Order Think Skills (HOTS).

In particular, the Ministry indications have foreseen three different teaching objectives:

- Digital literacy starting from elementary school (through coding);

- The "conversion" of students into "digital makers";

- A high level of teachers' training (for making possible the first two objectives.)

A platform called "Programma il Futuro" ("Future Program", www.programmafuturo.it) has been implemented for high school teachers and, in the current year, a course on "flipped classrooms" for Science and Computer Science teachers has started. Hence, a ministerial platform for training on these new kinds of technological classes has been arranged, and teachers and students have been allowed to register in order to attend both basic and advanced lessons.

However, pre-service teachers have been excluded from the process. In fact, only in-service teachers have had the possibility of attending the online course, on a volunteer basis.

In this view, all pre-service teachers, elementary school teachers, and teachers not specialized on Science or Computer Science have been out of this process, drastically. For example, an English high school teacher has not had 
the possibility of learning coding, and no training has been foreseen at a public level for elementary teachers (the most involved category in the process of digital literacy).

In this study, an educational setting for elementary pre-service teachers on digital literacy (using Scratch software, http://scratch.mit.edu) has been designed and implemented during a University course. Qualitative opinions on the technological experience have been collected in a report. The laboratory has been carried out at the University of Calabria (Italy), in a module of a Science of Education course for elementary pre-service teachers. In section 2, methodology using Scratch software has been defined. After qualitative results in section 3, conclusions are presented.

\section{Methodology}

\section{A. Subjects}

The sample consisted of sixty four students $(\mathrm{M}=13 ; \mathrm{F}$ $=51)$ aged between 18 and $40(\mathrm{M}=26 ; \mathrm{SD}=5.93)$, involved in a laboratorial module, Science of Education course, at University of Calabria (Italy).

In particular, only one subject was 40 years old, and she was attending courses for her second masters' degree.

Ethnical provenience and demographic makeup were homogeneous; an entry requests of information confirmed that participants were not familiar with technological devices, and that they have never used Scratch software.

Participants worked in groups. Research was carried out in a usual University classroom; the laboratorial module coexisted with other courses.

\section{B. Materials}

\section{1) The software Scratch}

Scratch 1.4 is a visual block-based programming language designed to promote media manipulation for novel programmers, created by the Lifelong Kindergarten Group at the MIT Media Lab. It can be easily used by novice programmers for the creation of interactive projects and applications (apps).

Images and sounds can be imported or created in Scratch using a building paint tool and sound recorder [12]. 2D objects called "sprites" act as avatars and involve states (variables) and behaviors (scripts).

Each script includes the sequence of instructions for the sprite behavior. In particular, each sprite has its independent set of scripts [11]; however, it is possible to manage multiple sprites with an identical behavior using the parallelism concept. One or more images can represent the various visual states of a sprite, and sounds (e.g. the "voice" of the sprites) can be played according to a specific design of behavior.

Scratch uses a drag and drop approach: programming is carried out by dragging command blocks from a palette into the scripting panel and assembling them, like puzzle pieces, to create "stacks" of blocks [11].

Regarding the interface, Scratch window has four main panels. In fact, it utilizes a single window, endowed with a multi panel design in order to ensure the contemporary vision of all key components. Hence, the software avoids floating palettes and minimizes the use of additional panels, that are showed on demand.

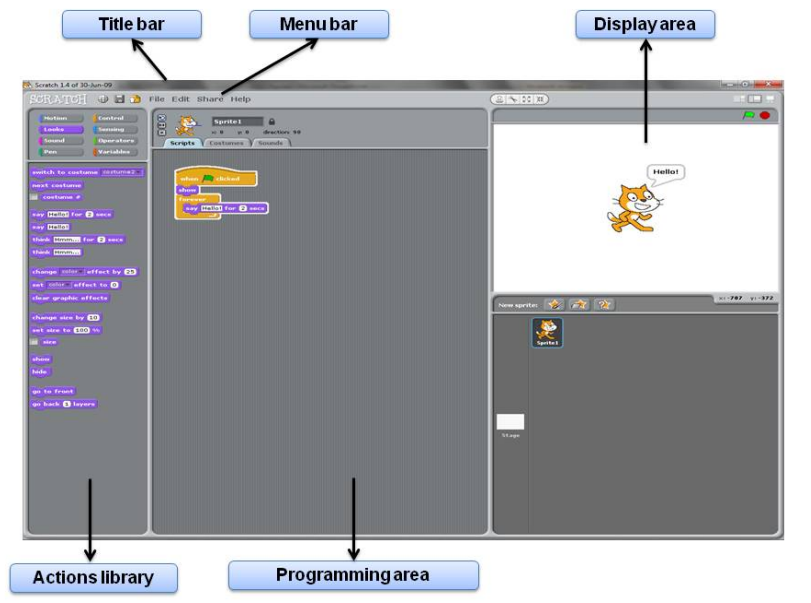

Figure 1. Interface of Scratch software, version 1.4 (http://scratch.mit.edu).

In the programming area, the left panel allows the selection of the kind of desired commands, whereas the middle panel shows the scripts for the currently selected sprite (with folder tabs to view and edit costumes and sounds).

The large panel on the upper right is the stage, where the action happens. It is 480 units wide and 360 units height, and it is divided into an $\mathrm{x}-\mathrm{y}$ grid. The center has an $\mathrm{x}$-coordinate of 0 and a y-coordinate of $0(0,0)[24]$.

A button on the bar under the stage allows a full screen display. Furthermore, the panel on the right, under the stage, shows the thumbnail of all the sprites present in the project, highlighting the selected sprite "Fig. 1".

For scripting, the command palette is always visible; command blocks are colored and divided into eight categories: blue for Motion, purple for Looks, violet for Sound, green for Pen, yellow for Control, light blue for Sensing, light green for Operators and orange for Variables.

The version of Scratch adopted in this research work (1.4) has 125 command blocks, even if some of them appear only when they are needed. In fact, the blocks to access variables and lists appear only after a variable or list is created.

As regards the number of command blocks, a strategy of reduction is the grouping of a set of related operations into a single block, using a drop-down menu to select the specific operation. Individual blocks or a stack of blocks start to work by a double-clicking.

Various blocks can be placed on the top of a stack of blocks to trigger a response to run-time events, such as program startup, pressing of a given key, or a mouse click on the sprite. Multiple stacks can run at the same time; blocks can be tested simply by clicking on them. A white border indicates that a block or stack is running.

Scratch is tinkerable (tinkerability is the capacity to understand how to improvise, adapt, and iterate, changing old plans when new situations arise). Hence, it encourages hands-on learning and supports a bottom-up approach for writing scripts where small chunks of code are assembled and tested, then combined into larger units. Blocks can be tested simply by clicking on them.

A white border indicates that a block or stack is running, whereas a red one is a feedback for an error "Fig. 2". 

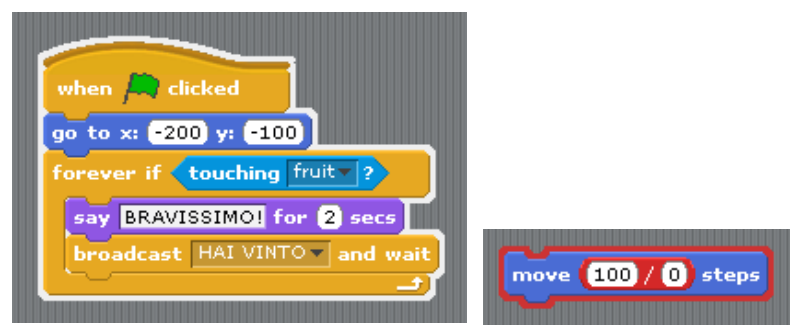

Figure 2. Blocks of commands in Scratch software.

There are four kinds of Scratch blocks: command blocks, function blocks, trigger blocks, and control structure blocks.

When command blocks are snapped together to create a sequence of commands, or stack, the notches and bumps fit together like puzzle pieces [10], [11].

Control structure blocks are a kind of command block with one or more nested command sequences.

Command blocks are like the statements of a text-based language.

Function blocks are like operators, not joined in linear sequences like command blocks. In fact, they are used as arguments of commands and nested together to build expressions.

Trigger blocks connect events (e.g. startup, mouse clicks, and key presses).

Taking into account the form of the blocks, in Scratch there are three main types of blocks in the Blocks Palette:

- Stack Blocks have bumps on the bottom and/or notches on the top. They can be snapped together into stacks.

- Hats have rounded tops and are placed at the top of stacks.

- Reporters fit in the input area of other blocks, reporting numbers or strings, and fitting in blocks with rounded or rectangular holes [24].

Regarding the Scratch website (http://scratch.mit.edu), different developments were studied and obtained during recent years.

Among these versions, Scratch 1.4 for personal computers and Scratch 2.0 (the online version launched in 2013 that now has also a PC version) "Fig. 3," can be cited.

In the website, users can upload their own projects, as well as animated stories, games, online news shows, book reports, greeting cards, music videos, science projects, tutorials, simulations and sensor-driven art and music projects.

Also, on line it is possible to get information for parents and teachers.

\section{2) Digital material on Scratch}

Digital material on how to learn coding was arranged and made available online. It consisted of the followings:

1. A power point presentation of 18 slides titled: "The hour of code" (an introduction to the laboratory);

2. A power point presentation called "Fun with Scratch", containing technical explanation on Scratch functioning:

- What is a computer

- Algorithms and Program concepts

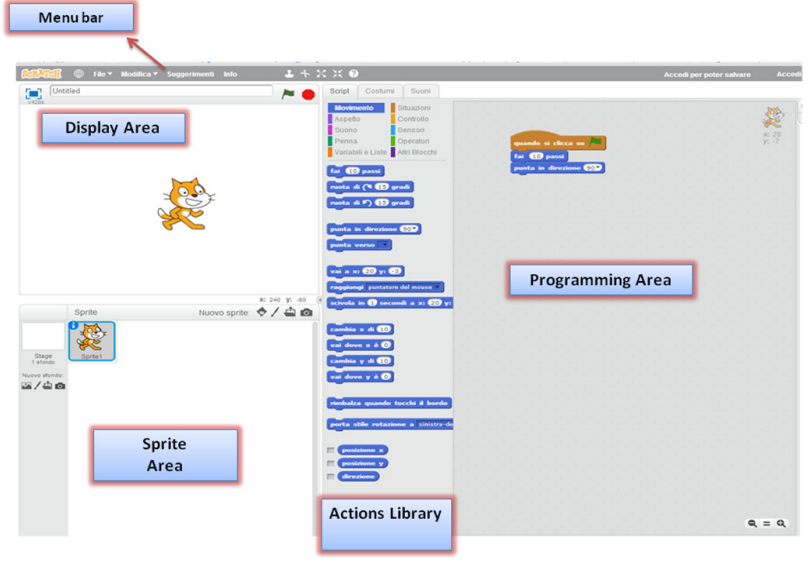

Figure 3. Scratch: version 2.0 (http://scratch.mit.edu)

- Programming languages definition and examples

- Scratch.- definition

- Beneficiaries

- What you can do with Scratch

- Sprites definition

- Scratch official website explanation

- Scratch download and installation

- Scratch interfaces, versions 1.4 and 2.0;

- Parts of the Scratch window.

- How to change the language

- The menu and options

- How to run a program

- Where are the sprites located

- Script definition, how to make a script in Scratch. Drag and drop.

- Blocks categories,

- First program, example

- Process to make a program

3. A power point presentation called "Blocks description" on the different categories of blocks and the principal functions (Scratch coding).

4. A power point presentation with an example of coding ("Help the cat to find the food"), ad hoc implemented by researchers.

5. A video with the complete explanation of the programming example, step by step;

\section{3) Hardware}

Participants used their own personal computers, downloading Scratch software from the following web site: http://scratch.mit.edu.

\section{Procedure}

Research included four phases. In the first phase, subjects attended two theoretical lessons on the use of Scratch software. In the second one, students utilized Scratch to ideate and implement an app. In the third phase, participants reported the negative and positive aspects of their experience during the course; afterwards, results were analyzed (fourth phase).

The laboratorial module was carried out in two months, and had a duration of 18 hours. 
In the first phase, programming was introduced to the elementary pre-service teachers by mentors "Fig. 4".

Afterwards, mentors helped to choose the educational app to develop and subjects were divided into groups on the basis of their personal interests.

In the second phase, groups implemented the application using Scratch. Mentors led the groups to reflect on the steps to realize the initial idea, the proper changes to set in order to implement the idea, the decision steps, the different possible solutions for the encountered problems, the opportunities, and the proposals. In particular, the focus was on the problem solving process and the user requirements.

In "Fig. 5," it is showed the work carried out by groups in the second phase. The use of Scratch (center of the figure) led to the realization of the application thanks to a team work (with its own group dynamic as leadership). On the left of the figure, connected with the realization of the app, the technical work is illustrated: from the choice of background and sprites to the creation of the scripts.

The implementation of the final project had a subsequent assessment, and revision/adjustments to the app were foreseen. On the right of the figure, connected again to the realization of the app, the mapping of the idea, the search of materials (e.g. the image of the proper sprite, a sound or music, or the realization of a voice) were foreseen. Both idea and materials led to the building of the narration in the app.

All the process was tutored by mentors, who provided feedbacks, allowing the revision of the app after the first assessment.

In the third phase, pre-service teachers had to compile a report on the experience, highlighting its positive and negative characteristics. In particular, subjects had to answer to two open questions: "Please indicate the positive aspects of your experience" and "Please indicate the negative aspects of your experience".

In the fourth phase, a qualitative data analysis approach was followed. Participant's personal data were coded, and each opinion was inserted in a dedicated tab page.

In particular, text synthesis were placed in a column and meaningful quotes were placed in another one. Afterwards, researchers coded the transcriptions according to their impact on the proposed methodology (e.g. opinion on the amount of work or personal engagement) and recommendations (e.g. on the arrangement of the setting).

Data were reorganized calculating percentages and summarizing the findings for each emerged element, also taking into account distinctions and conformities in reports. Results analyzed in the fourth phase are present in section III.

\section{RESULTS}

\section{A. Qualitative opinions on the experience}

In the report, pre-service teachers reported their opinion on the laboratorial experience, and results were positive. In particular, they judged their experience with Scratch as excellent $(91.67 \%)$ («I am very glad of the results gained in this course»; "I improved my skills together with my cultural background»; «It was an innovative training experience»), as well as a strong stimulus for creativity $(83.33 \%)$.

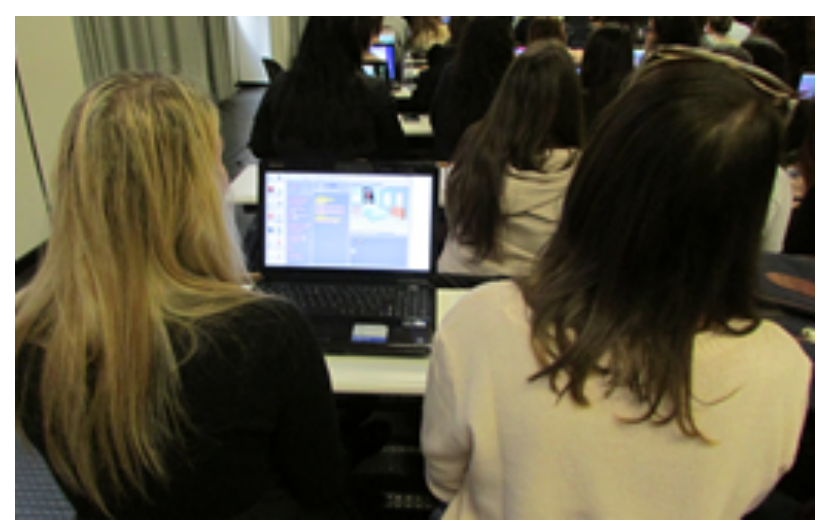

Figure 4. Students using Scratch during the first phase of the research

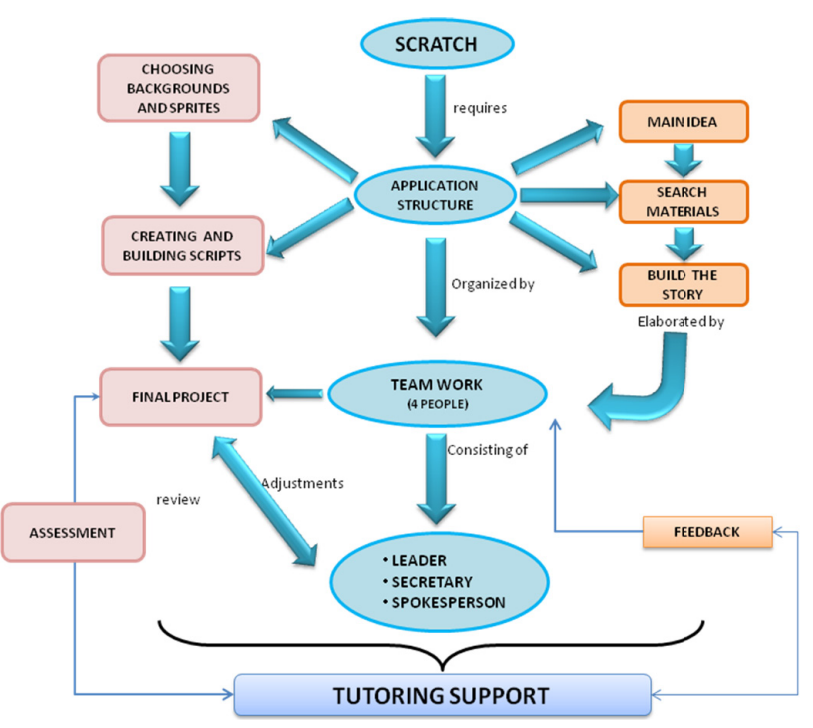

Figure 5. Process of the second phase of the research [12]

The freedom to code an app following their own interests was perceived as very pleasant. Collaborative work was pointed out by a high percentage of participants as enjoyable and motivating (79.17\%) («The opportunity of interacting with other pre-service teachers on unknown topics stimulated and motivated my group»; «Our team work stimulated the reflection on that carried out by students»; «Our group reflected on the disadvantages and advantages of a team work, and also divergence of opinions was a resource»). Moreover, in general, the arrangement of the course was considered as satisfying $(81.82 \%)$.

Emotions experienced by subjects during the project development were the following: desire to do a good work, disorientation during the first trials of coding, fulfillment at the end of the task.

Regarding the negative comments, an initial lack of predisposition was highlighted, and a constant concern regarded self-efficacy as future mentors who had to use technology in a classroom ( The progress forces us to learn the use of technological devices we never utilized»; «a teacher must not restrict students' imagination into his/her boundaries»)). Furthermore, a particular remark involved the hard work ( OOur team processed countless attempts and carried out a lot of evaluations of the app»).

Some subjects who strongly opposed the laboratorial approach during the course, in the report admitted to have learnt a lot on the use of computers ( $« \mathrm{We}$ must be more 
flexible and elastic»), and to have appreciated the group work. Even when they were not enthusiastic about being part of the laboratory, the use of the software was considered as engaging («the initial skepticism was totally unfounded»).

Results are in line with those of other researches [25], [26], [27]; [28], [29], and showed that negative stereotypes of people who are not digital natives as avoidant of technology and incapable of its use are outdated.

In fact, thanks to a suitable encouragement and an appropriate time schedule, pre-service teachers have the potential to become equally effective in using technology and computers as younger groups. Furthermore, since Scratch is considered as enjoying and engaging, it could be considered as a useful tool for Edutainment (the term refers to the mixture of the terms "education" and "entertainment").

Further studies are obviously necessary, including quantitative research measures in order to confirm the abovementioned preliminary data.

\section{B. Connection to the current situation in Italy}

Despite the enhanced availability of interactive whiteboard, computers, and tablets, the current use of technology in Italian school classroom is uncommon, especially in elementary classrooms.

The matter seems related to the lack of funds for public schools but, in a practical sense, many teachers refuse educational technologies because they have not studied them in a preliminary University stage. Furthermore, only in 2014 programming was introduced at school, and it has still a voluntary basis for teachers.

In 2015, the presence of a "digital organizer" was predisposed but not properly arranged. This delay is evident with respect to the current trends at an international level.

In this research, preliminary data show that laboratorial modules, arranged during University courses, could promote pre-service teachers' familiarization with the most used technologies at school. Following this approach, teachers could perceive themselves as effective mentors, and use technological devices in classroom.

\section{Limitations}

In this study, qualitative opinions have been collected, and quantitative measurement are necessary for valid findings and rigorous procedures.

As preliminary data, results are limited only to one group of pre-service teachers, and further studies are necessary.

Regarding the sample, female subjects were mainly involved, and different results could be obtained with male ones.

\section{CONCLUSIONS}

This study is part of a research carried out by the Laboratory of Psychology and Cognitive Science, operating at University of Calabria (Italy). Its design of a technology-enhanced setting endowed with coding tools as Scratch [30] was judged as potentially engaging and pleasant, even if pre-service teachers' highlighted their concern on the perception of self-efficacy. In this view, additional studies are necessary from a quantitative point of view (e.g. through the administration of motivation questionnaires).
Future developments could also foresee a deeper study on the dynamics of the teamwork.

Finally, the analysis of the projects that led to the realization of the app could be used to evaluate the improvement of the HOTS.

\section{REFERENCES}

[1] F. Bertacchini, L. Gabriele, \& A. Tavernise. Bridging Educational Technologies and School Environment: implementations and findings from research studies. In J. Hassaskhah (Ed.), Educational Theory. Series: Education in a Competitive and Globalizing World. Hauppauge, NY: Nova Science Publishers, Inc., 2011, pp. 63-82.

[2] F. Bertacchini, L. Gabriele, \& A. Tavernise. Looking at Educational Technologies through Constructivist School Laboratories: problems and future trends. Journal of Education Research, 6(2), 2012, pp. 235-239.

[3] F. Bertacchini, E. Bilotta, P. Pantano, \& A. Tavernise. Motivating the learning of science topics in secondary school: A constructivist edutainment setting for studying Chaos, Computers \& Education, 59 (4), 2012, pp. 1377-1386. http://dx.doi.org/10.1016/ j.compedu.2012.05.001.

[4] E. Bilotta, F. Bertacchini, L. Gabriele, \& A. Tavernise. Education and Technology: Learning By Hands-On Laboratory Experiences, Paper presented at the $3^{\text {rd }}$ International Conference on education and New Learning technologies - EduLearn 2011 Conference (6475-6483). L. Gómez Chova, D. Martí Belenguer, A. López Martínez (Eds), Ed. International Association of Technology, Education and Development IATED.

[5] D. H. Palmer. Situational interest and the attitudes towards science of primary teacher education students. International Journal of Science Education, 26, 2004, pp. 895 - 908. http://dx.doi.org/10.1080/0950069032000177262

[6] R. P. Hechter. Changes in Preservice Elementary Teachers' Personal Science Teaching Efficacy and Science Teaching Outcome Expectancies: The Influence of Context. Journal of Science Teacher Education, 22, 2011, pp. 187-202. http://dx.doi.org/10.1007/s10972-010-9199-7

[7] A. Roberts. Mentoring revisited: A phenomenological reading of the literature, Mentoring and Tutoring, (8)2, 2000, pp. 145-170. http://dx.doi.org/10.1080/713685524

[8] D.L. DuBois, \& M.J. Karcher. Youth mentoring: Theory, research and practice. In D.L. DuBois \& M.J. Karcher (Eds.) Handbook of youth mentoring, 2005, (pp. 2-12). Thousand Oaks: Sage. http://dx.doi.org/10.4135/9781412976664.n1

[9] Y. B. Kafai, S. Desai, K. A. Peppler, G.M. Chiu, \& J. Moya. Mentoring partnerships in a community technology centre: A constructionist approach for fostering equitable service learning, Mentoring \& Tutoring: Partnership in Learning, 16:2, 2008, pp. $191-$ 204. http://dx.doi.org/10.1080/13611260801916614

[10] J. Maloney, K. Peppler, Y. Kafai, M. Resnick, \& N. Rusk. Programming by Choice: Urban Youth Learning Programming with Scratch. 2008.

[11] J. Maloney, M. Resnick, N. Rusk, B. Silverman, \& E. Eastmond. The Scratch Programming Language and Environment. Massachusetts Institute of Technology. 2010.

[12] L. A. Vaca Cárdenas, F. Bertacchini, A. Tavernise, L. Gabriele, A. Valenti, D. Olmedo, P. Pantano, E. Bilotta, (2015). Coding with Scratch: The design of an educational setting for Elementary preservice teachers. Paper presented at the 18th International Conference on Interactive Collaborative Learning 2015, World Engineering Education Forum - ICL2015/WEEF. Special Session: "Talking about Teaching 2015" (TAT'15). 20-24 September 2015, Palazzo dei Congressi, Florence, Italy (pp. 1178-1184), Piscataway (NJ):IEEE.

[13] K. Koh. Adolescents' information-creating behavior embedded in digital media practice using Scratch," Journal of the American Society for Information Science and Technology. 64(9), 2013. pp. 1826-1841. http://dx.doi.org/10.1002/asi.22878

[14] G. Faraco, \& L. Gabriele, (2007). Using Labview for applying mathematical models in representing phenomena, Computers \& Education Volume: 49, Issue: 3, November, 2007, 856-872. http://dx.doi.org/10.1016/j.compedu.2005.11.025 
[15] E. Bilotta, L. Gabriele, R. Servidio, \& A. Tavernise. Motomanipulatory behaviours and learning: an observational study. International Journal of Online Engineering, 3(08), 2008, pp. 1317.

[16] E. Bilotta, L. Gabriele, R. C. Servidio, \& A. Tavernise. Edutainment Robotics as Learning Tool. Transactions on Edutainment, Nuova Serie, Vol. LNCS 5940, 2009, pp. 25-35.

[17] A Adamo, PA Bertacchini, E Bilotta, P Pantano \& A. Tavernise. Connecting Art and Science for Education: Learning by an Advanced Theatrical Environment with "Talking Heads", Leonardo Journal, MIT press, 43(5), 2010, pp. 442-448.

[18] A. Tavernise, \& F. Bertacchini. Virtual Laboratories as hands-on settings in Science education: some educational tools in the learning of Theory of Complexity and Chaos. In R. V. Nata (Editor). Progress in Education, 33, New York: Nova Science Publishers, Inc. 2015, pp. 77-87.

[19] L. Gabriele, A.Tavernise, \& F. Bertacchini. Active learning in an educational robotics laboratory: a case study with University students. In C. Wankel \& P. Blessinger (Eds.), Increasing Student Engagement and Retention Using Immersive Interfaces: Virtual Worlds, Gaming, and Simulation, Cutting-edge Technologies in Higher Education series. Bingley, UK: Emerald Publishing Group, 2012, pp. 315 - 339. http://dx.doi.org/10.1108/S20449968(2012)000006C014

[20] F. Bertacchini, E. Bilotta, L. Gabriele, P. Pantano, \& A. Tavernise. Towards the Use of Chua's Circuit in Education, Art, and Interdisciplinary Research: Some Implementation And Opportunities. Leonardo Journal, 46(5), 2013, pp. 456-464, http://dx.doi.org/10.1162/LEON_a_00641

[21] F. Bertacchini, E. Bilotta, L. Gabriele, P. Pantano, \& A. Tavernise. Designing an educational music software using a student-centred strategy. In R. V. Nata (Editor). Progress in Education, 33, New York: Nova Science Publishers, Inc., 2015, pp. 89-99.

[22] L. Vaca Cárdenas, D. Olmedo Vizueta, A. Tavernise, L. Gabriele, F. Bertacchini, P. Pantano \& E. Bilotta. Darwin has come back to the Galápagos Islands: an educational journey to discover biological evolution. Proceedings of the 6th international conference on education and new learning technologies - EduLearn 14,7-9 July, 2014, Barcelona (Spain), pp. 6088 - 6095. L. Gómez Chova, A. López Martínez, I. Candel Torres (Eds.), Ed. IATED: CD Rom, ISBN: 978-84-617-0557-3.

[23] L. Vaca Cárdenas, F. Bertacchini, L. Gabriele, A. Tavernise, D. E. Olmedo, P. Pantano, E. Bilotta. Surfing Virtual Environment in the Galápagos Islands - Edutainment for improving the learning of STEAM. Paper presented at the 12th International Conference on Remote Engineering and Virtual Instrumentation - REV2015, 25-28 February 2015, Bangkok, Thailand (pp. 199-205), Usa: IEEE Xplore ${ }^{\circledR}$ Publication. ISBN: 978-1-4799-7838-0, (Scopus ID E915833EB7D3A978A4B3E3C64C8E36C4). http://dx.doi.org/10.1109/REV.2015.7087291

[24] Scratch Reference Guide of MIT

[25] P. Turner, S. Turner, \& G. Van DeWalle. How older people account for their experiences with interactive technology. Behaviour and Information Technology, 26(4), 2007, pp. 287-296. http://dx.doi.org/10.1080/01449290601173499

[26] K. Brennan. Best of both worlds: issues of structure and agency in computational creation, in and out of school. Thesis in Media Arts and Sciences at the Massachusetts Institute of Technology. 2013.

[27] S. Dasgupta, \& M. Resnick. Engaging Novices in Programming, Experimenting, and Learning with Data. ACM Inroads, 5(4), 2014, pp. 72-75. http://dx.doi.org/10.1145/2684721.2684737

[28] M. Guzdial. Programming environments for novices. In S. Fincher and M. Petre (Eds.), Computer Science Education Research, 2004, pp. 127-154. Lisse, The Netherlands: Taylor \& Francis.

[29] N. Forsgren Velasquez, D. A. Fields, D. Olsen, H. T. Martin, A. Strommer, M. C. Sheperd, \& Y. B. Kafai. Novice programmers talking about projects: What automated text analysis reveals about online Scratch users' comments. Paper presented at the Annual Hawaii International Conference on System Sciences (HICSS). Waikoloa, Hawaii. IEEE. 2014.

[30] D.E. Olmedo, L. Vaca Cárdenas, L. Gabriele, A. Tavernise, F. Bertacchini, P. Pantano and E. Bilotta, "A video-modeling system for improving social skills and lexicon in autistic spectrum disor- der children," EDULEARN 2014, pp. 6081-6087, ISBN: 978-84617-0557-3.

\section{AUTHORS}

L. Vaca-Cárdenas is with the Physics Department, University of Calabria, Rende, Italy. She is a Ph.D Student, member of the Evolutionary System Group (ESG) (http://galileo.cincom.unical.it/). She is a Systems Engineer and she has a Master degree in University Teaching and Educational Research. Her research interests are focused in the following topics: E-learning Systems, Virtual Learning platforms, Information and Communication Technologies (ICTs), Internet of Things (IoT), Virtual Reality, Games and programming tools for education (leticiavcec@yahoo.com).

A. Tavernise is with the Physics Department, University of Calabria, Rende - Cosenza, Italy. She is a Contract Professor at University of Calabria, and a member of both the Laboratory of Psychology and Cognitive Science and the research group called Evolutionary Systems Group (ESG, http://galileo.cincom.unical.it/). The focus of her research is the design and implementation of educational settings/paths in technology-enhanced contexts in order to investigate the acquisition of high level cognitive skills (as critical thinking, problem solving, creativity, collaboration) and, in particular, learning. Many of her research results were achieved in national and international projects, as for example Connecting European Culture through New Technology - NetConnect (EU project, financed in the programme Culture2000) and Virtual $\mathrm{Mu}-$ seum System (national projects POR 2000-2006) (assunta.tavernise@unical.it).

F. Bertacchini is with the Mechanical, Energy and Management Engineering Department, University of Calabria, Rende, Italy. She is a Ph.D in "Psychology of Programming and Artificial Intelligence", and a Post-Doc Fellow. She is a member of the research group ESG (http://galileo.cincom.unical.it/), and works in the Laboratory of Psychology and Cognitive Science at University of Calabria, designing educational-entertaining environments for science communication and education. Among her research interests we can cite the followings: Educational Technologies, Art \& Science, Scientific Visualization, Psychology of Music (francescabertacchini@live.it).

L. Gabriele is with the Physics Department, University of Calabria, Rende, Italy. She is a post-doc Fellow and is interested in the following topics: psychology of programming, educational technologies and their use in didactic context, learning, techniques of Human Computer Interaction, communications systems and their use for educational purposes. She is an occasional referee of the journals Computers \& Education, Scientific Research and Essays, and member of the Editorial Board of the Journal of Applied Research in Higher Education (JARHE). She worked in different national and international projects (lorella.gabriele@unical.it).

A. Valenti is with the Humanities Study Department, University of Calabria, Rende, Italy. She is an Associated Professor at the University of Calabria and the director of the Primary Education Science Course Degree. Her research interests concern the following scientific topics: Special Educational Needs; Autism and learning; Advanced learning environments; e-learning systems to support subjects with disabilities (antonella.valenti@) unical.it). 
P. Pantano is with the Physics Department, University of Calabria, Rende, Italy. He is a full Professor of Physics and Mathematics at University of Calabria. His main research interests concern several topics according to an interdisciplinary approach, among which we can cite the followings: e-Learning systems; Scientific communication; Artificial life. He is a member of several national and international scientific communities, scientific committees and organized several congresses and workshops. From 2011 is the director of a Doctoral School at University of Calabria. He participated in national and international projects as responsible of local research unit as well as international coordinator (pietro.pantano@unical.it).

E. Bilotta is with the Physics Department, University of Calabria, Rende, Italy. She is a full professor of Gen- eral Psychology at University of Calabria, Italy, where she is also the director of the Cognitive Psychology Laboratory. Her research interests concern various scientific topics from an interdisciplinary point of view and comprise the following areas: Human Computer Interaction, Psychology of Programming, Information and communication technologies, Educational Technologies. She published more than 200 scientific papers and is the author of various books. She was the coordinator of (or participated in) national and international projects. Moreover, she is a member of several national and international scientific communities (eleonora.bilotta@unical.it).

Submitted, 14 December 2015. Published as resubmitted by the authors on 14 January 2016. 